\title{
VISITA DOMICILIAR MULTIPROFISSIONAL SOB A ÓTICA DA ESTRATÉGIA EM SAÚDE DA FAMÍLIA (ESF) EM COLOMBO/PR
}

Ana Eliza ARTICO, Juliana Balbi OLIVEIRA, Carla Vanessa ALVES, Marilene BUfFON

Neste relato, foi selecionada uma família para estudo de caso em Saúde Bucal, onde contamos com uma Equipe Multiprofissional, composta por: cirurgião- dentista, farmacêutico e nutricionista. Foram realizadas cinco visitas para a família. No primeiro contato foi feito reconhecimento da família e criação de vínculo, em seguida o cirurgião-dentista junto com a nutricionista coletaram alguns dados dos hábitos alimentares da família, pesagem, reconhecimento dos problemas de saúde, e as identificações de cada integrante da família para que assim fosse possível ter um olhar mais amplo sobre a família. Em outra oportunidade, foi realizado exame clínico e anamnese da saúde bucal nos familiares presentes. Dos cincos familiares, quatro necessitaram de tratamento odontológico onde dois foram encaminhados para tratamento imediato e para a criança menor orientações à mãe sobre o uso da mamadeira. Em uma das visitas o profissional farmacêutico pode contribuir no trabalho com a família, esclarecendo dúvidas sobre as medicações e o uso racional. Neste estudo foram aplicadas as ferramentas da ESF: ciclo de vida e genograma. Com os dados, complementaram-se as orientações sobre o auto-cuidado considerando as características da família e possibilitou a aplicação de medidas educativas e preventivas com vista à promoção da saúde geral.

Palavras-chave: Visita domiciliar, Ciclo de vida, Saúde bucal. 